\title{
PHOTOCHEMICAL DEPOSITION OF Pd-LOADED AND Pt-LOADED TIN OXIDE THIN FILMS.
}

\author{
G.E. BUONO-CORE ${ }^{*}$, G.A. CABELLO', H. ESPINOZA', A.H. KLAHN ${ }^{1}$, M.TEJOS ${ }^{2}$, R.H. HILL \\ ${ }^{1}$ Intituto de Química, Pontificia Universidad Católica de Valparaíso, Valparaíso (Chile) \\ ${ }^{2}$ Facultad de Ciencias, Universidad de Valparaíso, Valparaíso (Chile) \\ ${ }^{3}$ Department of Chemistry, Simon Fraser University, Burnaby, B.C. V5A 1S6 (Canada)
}

\begin{abstract}
Pd and Pt loaded tin oxide thin films have been successfully prepared by direct UV irradiation of amorphous films of $\beta$-diketonate complexes on Si(100) substrates. Tin oxide films loaded with 10,30 and 50\% Pd and Pt, were characterized by Auger electron spectroscopy (AES). The Auger peak intensity ratios of O $\mathrm{KL}_{23} \mathrm{~L}_{23}$ to $\mathrm{Sn} \mathrm{M}_{4} \mathrm{~N}_{45} \mathrm{~N}_{45}$ showed that as-deposited films consist of mixed tin oxide phases whereas annealed films consist mainly of single phase $\mathrm{SnO}_{2}$. The results showed that the stoichiometry of the resulting films is in relative agreement with the composition of the precursor films. The surface characterization of these thin films was performed using Atomic Force Microscopy (AFM). This analysis revealed that loaded tin oxide films have a much rougher surface than unloaded films, with rms roughness values ranging from $28-54 \mathrm{~nm}$ for as-deposited $\mathrm{Pd}-\mathrm{SnO}_{\mathrm{x}}$ films to $3.6-20 \mathrm{~nm}$ for as-deposited Pt-SnO films. It was also found that Pt-loaded tin oxide films present a better particle size distribution and uniformity when compared to Pd-loaded tin oxide films. These results demonstrate the potential use of these deposited films in the manufacture of gas-sensing devices.
\end{abstract}

Keywords: Tin oxide; Platinum; Palladium; photodeposition; thin films.

\section{INTRODUCTION}

In the last few decades the research interest in the gas-sensing field via semiconductor based devices has noticeably increased with a particular interest in the development of new materials. In this respect, a big effort is a being exercised in the search for sensitive and selective materials. The functional properties of the materials depend on their microstructure (grain and agglomerate size, porosity, roughness, etc) and composition (doping, deviation from stoichiometry) [1]. In general, structural characteristics, depending on deposition conditions, have great effects on properties of materials [2].

Zinc oxide $(\mathrm{ZnO})$ and tin dioxide $\left(\mathrm{SnO}_{2}\right)$ have long been used as gas sensing materials [3-6]. Although the oxides themselves are catalytically active, they are rarely used in isolation as their gas sensing characteristics are usually enhanced by the addition of small amounts of noble metal catalysts such as palladium or platinum which not only promote gas sensitivity but also improve the response times [4].

It has been shown that for $\mathrm{SnO}_{2}$ films doped with noble metals, such as $\mathrm{Pt}$ and $\mathrm{Pd}$, there is a decrease in operation temperature and enhancement of sensitivity to different gases $[7,8]$. Under noble metal loading, it is expected that clusters form at the surface of $\mathrm{SnO}_{2}$ such as those observed in the case of Pd [9] and Pt [10]. These clusters will be in metallic or oxidized forms depending on the noble metal, the deposition process, the interacting gas and the sensor operation temperature.

$\mathrm{SnO}_{2}$ thin films have been prepared by a variety of deposition techniques and noble metal additives can be introduced in several ways into a sensor: eg., sputtering and posterior thermal treatment $[11,12]$, sol-gel techniques $[13,14]$, and chemical vapour deposition $[15,16]$ among others.

In the last few years we have developed a novel photochemical method for the deposition of a variety of metals and metal oxides thin films [17-19], which can be carried out at ambient temperature, from simple precursor compounds. This method consists in the direct irradiation of thin films of coordination complexes with ultraviolet light. The simplicity of the method allows for the deposition of very thin films of metallic materials or metallic oxides, depending on the reactions conditions, on substrates which are not affected by the UV light. The development of this method requires that the precursor complexes form stable amorphous thin films upon spin coating onto a suitable substrate and that photolysis of these films result in the photoextrusion of the ligands leaving the inorganic products on the surface (Eq 1).

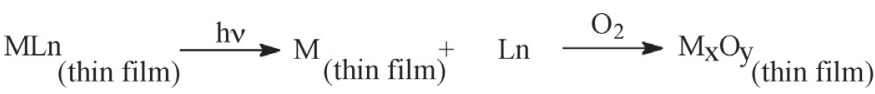

where $\mathrm{M}=$ Metal; $\mathrm{L}=$ ligand

In this work we report on the preparation and characterization of tin palladium and platinum complexes to be used as source materials for the direct photochemical deposition of $\mathrm{SnO}_{\mathrm{x}}, \mathrm{Pd}-\mathrm{SnO}_{\mathrm{x}}$ and $\mathrm{Pt}-\mathrm{SnO}_{\mathrm{x}}$ thin films.

\section{EXPERIMENTAL}

\section{General procedure}

The FT-IR spectra were obtained with $4 \mathrm{~cm}^{-1}$ resolution in a Perkin Elmer Model 1605 FT-IR spectrophotometer. UV spectra were obtained in a HewlettPackard 8452-A diode array spectrophotometer. X-ray diffraction patterns were obtained using a D5000 X-ray diffractometer. The X-ray source was $\mathrm{Cu}$ $40 \mathrm{kV} / 30 \mathrm{~mA}$. Auger electronic spectra were obtained using a PHI double pass CMA at $0.85 \mathrm{eV}$ resolution at the Surface Physics Laboratory, Department of Physics, Simon Fraser University. Sensitivity factors provided by PHI were used to obtain normalized Auger intensities. Atomic Force Microscopy was performed in a Nanoscope IIIa (Digital Instruments, Santa Barbara, CA) in contact mode. Film thickness was determined using a Leica DMLB optical microscope with a Michelson interference attachment.

Solution photochemistry was carried out in $1 \mathrm{~cm}$ quartz cells, which were placed in a Rayonet RPR-100 photoreactor equipped with $254 \mathrm{~nm}$ lamps. Progress of the reactions was monitored by determining the UV spectra at different time intervals, following the decrease in UV absorption of the complexes. The solid state photolysis was carried out at room temperature under a UVS-38 $254 \mathrm{~nm}$ lamp equipped with two $8 \mathrm{~W}$ tubes, in an air atmosphere.

The substrates for deposition of films were borosilicate glass microslides (Fischer, $2 \times 2 \mathrm{~cm})$ and p-type silicon(100) wafers $(1 \times 1 \mathrm{~cm})$ obtained from WaferNet, San Diego, CA. Prior to use the wafers were cleaned successively with ether, methylene chloride, ethanol, aqueous HF (50:1) for 30 seconds and finally with deionized water. They were dried in an oven at $110^{\circ} \mathrm{C}$ and stored in glass containers.

\section{Synthesis of $\beta$-diketonate complexes.}

The reagents used in the synthesis of tin, palladium and platinum $\beta$ diketonates were from Aldrich Chemical Co., and where used without previous purification. The method reported by Adams and Hauser [20,21] was used to obtain the $\beta$-diketonate, 1-phenyl-1,3-nonanedione. FT-IR data (film) $v$ $1700(\mathrm{~s}), 1602(\mathrm{~s}), 1560(\mathrm{~s})$; UV-Vis data $\lambda(\log \varepsilon)$ in $\mathrm{CH}_{2} \mathrm{Cl}_{2}: 314 \mathrm{~nm}(3.76)$, $248 \mathrm{~nm}$ (3.51). The sodium salt used in the synthesis of the tin complex, was prepared by the method previously described in the literature [21].

\section{Bis (1-phenyl-1,3-nonanedionato) Sn(II)}

The tin complex was prepared according to reported method [22,23]. Stannous chloride $(1.0 \mathrm{~g}, 5.27 \mathrm{mmol})$ and $\mathrm{Na}(1$-phenyl-1,3-nonanedionato) $(2.42 \mathrm{~g}, 10.54 \mathrm{mmol})$ were loaded in a $250 \mathrm{~mL}$ flask under a nitrogen atmosphere. After addition of $80 \mathrm{~mL}$ of THF to the flask, the solution mixture was stirred at room temperature for $2 \mathrm{~h}$. After filtration of the solution and removal of THF a pale yellow liquid was obtained. Purification of the crude product by distillation under reduced pressure afforded pale yellow $\mathrm{Sn}\left(\mathrm{L}_{1}\right)_{2}$ (70.3\% yield). FT-IR data (film): $v_{\mathrm{co}} 1597.2(\mathrm{~s}), 1525(\mathrm{~s}) \mathrm{cm}^{-1}$. UV-Vis data $\lambda$ $(\log \varepsilon)$ in $\mathrm{CH}_{2} \mathrm{Cl}_{2}: 330 \mathrm{~nm}(4.22), 254 \mathrm{~nm}$ (3.97), $232 \mathrm{~nm}$ (3.99). Anal: Calcd. for $\mathrm{C}_{20} \mathrm{H}_{18} \mathrm{O}_{4} \mathrm{Sn}$ : ${ }^{\mathrm{C}}, 54.47$; $\mathrm{H}, 4.11$. Found: $\mathrm{C}, 54.41 ; \mathrm{H}, 4.06$. 
Synthesis of $\beta$-diketonate Pd(II) and Pt(II) complexes.

For the synthesis of the Bis(1-phenyl-1,3-butanodionate)M(II) complexes where $\mathrm{M}=\mathrm{Pt}$ or Pd, a method reported by $\mathrm{W}$. Lin et al. was used [24]. To an aqueous solution of $\mathrm{NaOH}(250 \mathrm{mg}$ in $10 \mathrm{~mL})$ is added benzoylacetone $(2$ $\mathrm{mmol}$ ) under constant stirring. After the addition of $1 \mathrm{mmol}$ of the corresponding metal salt, $\mathrm{PdCl}_{2}$ or $\mathrm{PtCl}_{2}$, the mixture is stirred for $24 \mathrm{~h}$ at room temperature. The crude product is filtered and dried under vacuum, after which is purified by passing through a column packed with silica gel. The solvent is evaporated at room temperature until crystals are obtained. The pure complexes were characterized by FT-IR and elemental analysis.

(a) Bis(1-phenyl-1,3- butanodionate)Pd(II):

FT-IR data (film) $v_{\text {со }} 1585(\mathrm{~s}), 1545(\mathrm{~s}), 1514(\mathrm{~s})$

UV-Vis data $\lambda(\log \varepsilon)$ in $\mathrm{CH}_{2} \mathrm{Cl}_{2}: 354 \mathrm{~nm}(4.21), 258 \mathrm{~nm}$ (4.55), $232 \mathrm{~nm}$ (4.47)

Anal. Calcd. for $\mathrm{C}_{20} \mathrm{H}_{18} \mathrm{O}_{4} \mathrm{Pd}$ : C, 56.02; H, 4.23; Found: C, 56.04; H, 4.10.

(b) Bis(1-phenyl-1,3- butanodionate)Pt(II):

FT-IR data (film) $v_{\text {Co }} 1580(\mathrm{~s}), 1518(\mathrm{~s}), 1486(\mathrm{~s})$

UV-Vis data $\lambda(\log \varepsilon)$ in $\mathrm{CH}_{2} \mathrm{Cl}_{2}: 310 \mathrm{~nm}(4.56), 250 \mathrm{~nm}$ (4.28), $232 \mathrm{~nm}$ (4.21)

Anal. Calcd. for $\mathrm{C}_{20} \mathrm{H}_{18} \mathrm{O}_{4} \mathrm{Pt}$ : C, 46.42; H: 3.51; Found: C, 46.21; H, 3.49 .

\section{Preparation of amorphous thin films}

Thin films of the precursors complexes were prepared by the following procedure: a silicon chip was placed on a spin-coater. A portion $(0.2 \mathrm{ml})$ of the solution of $\beta$-diketonate complex in $\mathrm{CH}_{2} \mathrm{Cl}_{2}$ was dispensed onto the silicon chip which was then rotated at a speed of $1500 \mathrm{rpm}$. Once the solvent evaporated, the motor was stopped and a thin film of the complex remained on the chip. The quality of the thin films was examined by optical microscopy (1000x magnification).

\section{Photolysis of complexes as films on $\mathrm{Si}(100)$ surfaces.}

All photolysis experiments were done following the same procedure. Here is the description of a typical experiment. A film of the diketonate complex was deposited on p-type $\mathrm{Si}(100)$ by spin-coating from a $\mathrm{CH}_{2} \mathrm{Cl}_{2}$ solution. This resulted in the formation of a smooth, uniform coating on the chip. The FTIR spectrum of the starting film was first obtained. The chip was then placed under a UVS $254 \mathrm{~nm}$ lamp. After the FT-IR spectrum showed no evidence of the starting material, the chip was rinsed several times with dry acetone to remove any organic products remaining on the surface, prior to analysis. When glass substrates were used for deposition, the progress of the reactions was monitored by UV-Vis spectroscopy.

\section{RESULTS AND DISCUSSION}

The electronic spectra of thin films of the $\mathrm{Sn}^{+2}$ complexes exhibited bands at 254 and $330 \mathrm{~nm}$ aprox. The observed absorption bands have been assigned to the various electronic transitions, the band at $254 \mathrm{~nm}$ corresponding to LMCT transition (ligand-to-metal charge transfer) while the absorption at $330 \mathrm{~nm}$ being assigned to an intraligand $\pi \square \pi^{*}$ transition. Although the photochemistry of several transition metal 1,3-diketonates has been extensively investigated $[25,26]$, no reports can be found in the literature concerning Sn complexes. We therefore carried out experiments to evaluate the photosensitivity of the Bis(1-phenyl-1,3-nonanedionato)Sn(II) complex in solution and as a film. In a previous paper we reported that when dichloromethane solutions of this complex were photolyzed with $254 \mathrm{~nm}$ UV light, a complete disappearance of the absorption bands of the complex could be observed after $30 \mathrm{~min}$ of irradiation [19]. This result demonstrates that the Sn diketonate complex is highly photoreactive in solution and that the photochemistry is initiated through the irradiation of the LMCT band at $254 \mathrm{~nm}$.

In order to investigate the solid state photochemistry, films of the Sn complex were deposited on ITO glass by spin-coating and irradiated under air atmosphere with a $254 \mathrm{~nm}$ UV source. This led to the decrease of the absorptions associated with the ligand, as shown by the UV-Vis monitoring of the reaction (Fig. 1).

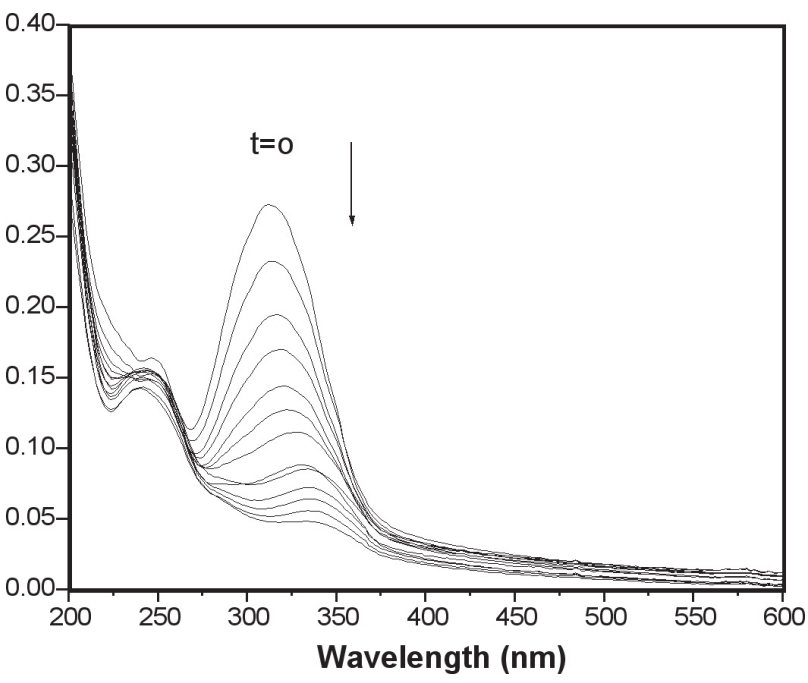

Fig. 1. Changes in the UV spectrum of Bis(1-phenyl-1,3nonanedionato) $\mathrm{Sn}$ (II) complex thin film deposited on ITO glass upon $\sim 7 \mathrm{~min}$ irradiation with $254 \mathrm{~nm}$ light (30 seg intervals).

The as-deposited tin oxide thin films on $\mathrm{Si}(100)$ substrate obtained by irradiation of $\mathrm{Sn}(\mathrm{II})$ diketonate complex were characterized by Auger electronic spectroscopy. In the AES spectrum (Fig. 2) is possible to observe a well resolved doublet signal at 423.8 and $432.2 \mathrm{eV}$ corresponding to the $\mathrm{Sn}$ MNN transition assigned as $\left(\mathrm{M}_{4} \mathrm{~N}_{45} \mathrm{~N}_{45}\right)$ and $\left(\mathrm{M}_{5} \mathrm{~N}_{45} \mathrm{~N}_{45}\right)$. On the other hand, the oxygen signal was observed at $510.6 \mathrm{eV}$ and associated to the $\mathrm{KL}_{23} \mathrm{~L}_{23}$ transition. It has been established in some works $[27,28]$ that the doublet signal for $\mathrm{Sn}$ in oxidized form appears clearly defined at 425 and $432 \mathrm{eV}$ and the oxygen transition has been assigned to $510 \mathrm{eV}$. On the other hand, results reported for Sn metallic have indicated that the doublet signal is less resolved and shifted to higher energy values by approximately $5 \mathrm{eV}$. Values of 430 and $437 \mathrm{eV}$ have been reported [27,28]. According to these results the as-deposited films show the formation of $\mathrm{Sn}$ in the oxidized form in an intermediate state, with little or nothing of Sn metallic present. Furthermore, an analysis after bombardment with $\mathrm{Ar}^{+}$ions, showed only the presence of $\mathrm{Sn}$ in a $45.4 \%$ and oxygen in a $54.6 \%$, with no signs of carbon contamination in the as-deposited films. The intensity ratio between the $\mathrm{O}$ and $\mathrm{Sn}$ Auger signals corresponds to a composition of $\mathrm{SnO}_{1.2}$. The oxygen stoichiometry was estimated from the ratio of the Auger peak-to-peak heights of the $\mathrm{O}(\mathrm{KLL})$ line at a kinetic energy of $510.6 \mathrm{eV}$ and the low-energy feature of the $\mathrm{Sn}(\mathrm{MNN})$ doublet at $423.8 \mathrm{eV}$.

Attempts to get an XRD spectrum of the as-deposited films were unsuccessful, which demonstrate the amorphous character of these films. Only after annealing at $900^{\circ} \mathrm{C}$ for $2 \mathrm{~h}$ in a continuous flow of synthetic air, X-ray diffraction peaks could be observed, at $2 \theta$ angles of $26.61,33.89$ and 37.95 degrees associated with the (110), (101) and (200) planes of tetragonal $\mathrm{SnO}_{2}$ [JCPDS 21-1250].

Auger spectrum of the annealed film was determined and is shown in Fig. 3. It shows that the annealing treatment changes the shape of the Sn doublet and the $\mathrm{O} / \mathrm{Sn}$ intensity ratio significantly, which results in a composition of approximately $\mathrm{SnO}_{1.9}$. This broadening of the original peaks due to annealing may be attributed to different chemical environments of the tin atoms. Similar line distortions have been reported for as-deposited and annealed $\mathrm{SnO}$ films prepared by ion-beam assisted deposition [29]. 


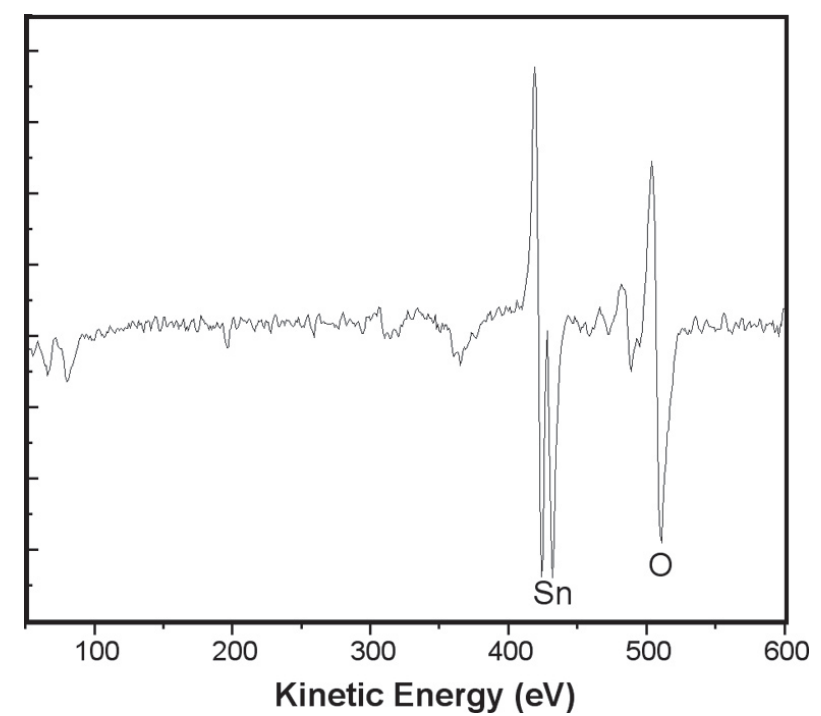

Fig 2. Auger survey spectrum of an as-deposited $\mathrm{SnO}_{\mathrm{x}}$ film (220 nm thick) photodeposited from $\operatorname{Bis}(1$-phenyl-1,3-nonanedionato)Sn(II) after sputtering with $\mathrm{Ar}^{+}$for $120 \mathrm{~s}$.

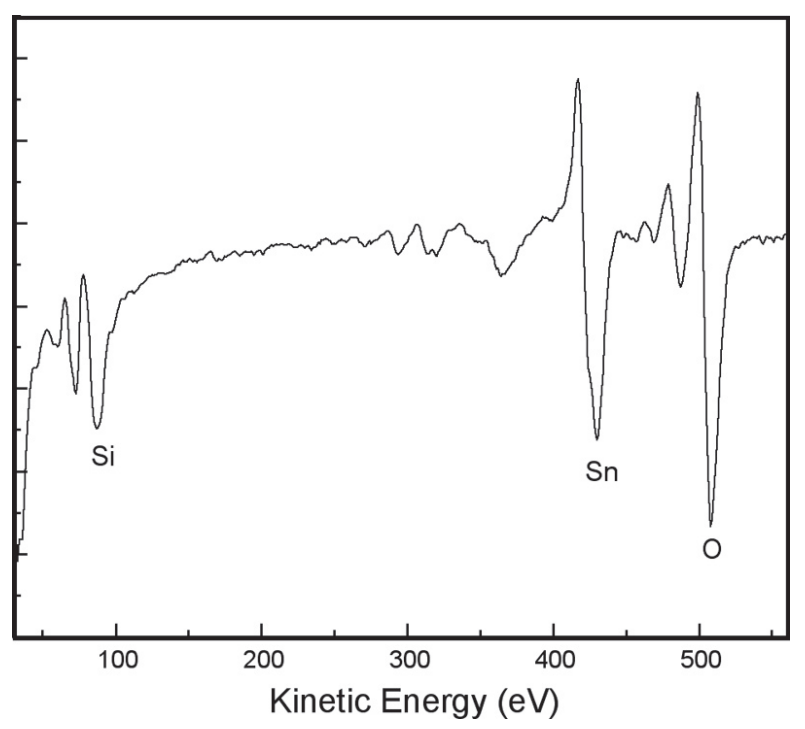

Fig 3. Auger survey spectrum of a $\mathrm{SnO}_{\mathrm{x}}$ film $(220 \mathrm{~nm}$ thick) photodeposited from Bis(1-phenyl-1,3-nonanedionato) Sn(II) and annealed at $900^{\circ} \mathrm{C}$ for $2 \mathrm{~h}$ under a flow of synthetic air.

AFM analysis revealed that the as-deposited $\mathrm{SnO}_{\mathrm{x}}$ films (thickness $=220$ $\mathrm{nm})$ have a rough surface morphology with a rms roughness of $17.7 \mathrm{~nm}(\mathrm{R}=$ $226 \mathrm{~nm}$ ) as shown in Fig 4. In these films, grains are not well packed on the substrate, leaving relatively large mesopores in the films, and consequently having high porosity. These results are important since it has been reported that thickness and porosity of semiconductor films strongly influence the gas sensing properties to $\mathrm{CO}, \mathrm{H}_{2}$ and $\mathrm{LPG}$ [7].

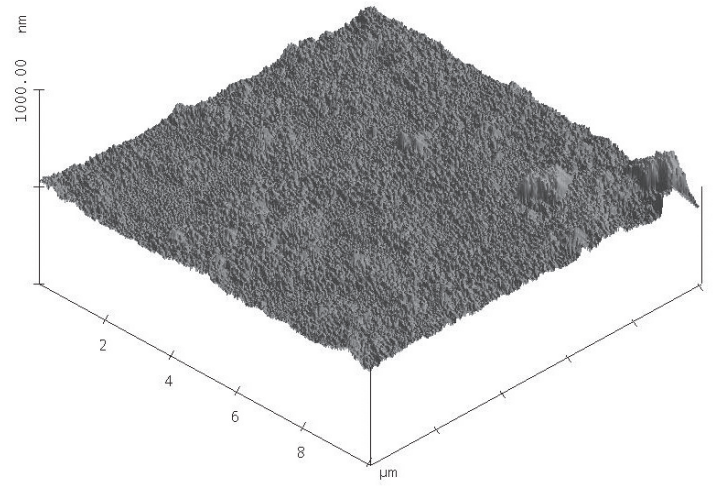

Fig 4. AFM micrograph of an as-deposited amorphous $\mathrm{SnO}_{\mathrm{x}}$ film photodeposited on $\mathrm{Si}(100)$ from $\operatorname{Bis}(1-$ phenyl-1,3-nonanedionato) $\mathrm{Sn}(\mathrm{II})$. Image size: $10 \times 10 \mu \mathrm{m}$. Z-scale: $1000.0 \mathrm{~nm}$.

Characterization of Metal (M)-loaded $\mathrm{SnO}_{\mathrm{x}}$ thin films (M= Pt or Pd).

Precursor films were prepared by dissolving Bis(1-phenyl-1,3nonanedionato) $\mathrm{Sn}(\mathrm{II})$ with 10,30 and $50 \%$ of $\mathrm{Bis}(1-$ phenyl-1,3butanedionato) $\mathrm{M}(\mathrm{II})$ (where $\mathrm{M}=\mathrm{Pt}$ or $\mathrm{Pd}$ ) (with respect to $\mathrm{Sn}$ complex) in $\mathrm{CH}_{2} \mathrm{Cl}_{2}$ and spin-coating at $1500 \mathrm{rpm}$ on a silicon(100) substrate. After examination of the films by optical microscopy (1000x magnification), they were irradiated under a UV light $(254 \mathrm{~nm})$ for $48 \mathrm{~h}$ under air atmosphere. The FT-IR spectrum of the precursors deposited on $\mathrm{Si}(100)$ was easily detected and was used to monitor the reaction throughout the photochemical process. The loss of starting material was clearly evident, and at the end of the photolysis, after a $48 \mathrm{~h}$ irradiation period, there were no detectable absorptions associated with the diketone ligands in the FT-IR spectrum.

\section{Pd-loaded $\mathrm{SnO}_{\mathrm{x}}$ thin films.}

Auger electron spectra for Pd loaded $\mathrm{SnO}_{\mathrm{x}}$ films (10, 30, $50 \%$ of $\left.\mathrm{Pd}\right)$ are represented in the Figs 5(a), 5(b) and 5(c) respectively. AES analysis for tin metal, establish that the $\mathrm{M}_{4} \mathrm{~N}_{45} \mathrm{~N}_{45}$ transition for metallic Sn appears weakly in the form of doublet and shifted to higher kinetic energy ( 430 and $437 \mathrm{eV}$ ) with regard to the oxidized form of the Sn. These displacements to higher energy (near $5 \mathrm{eV}$ ), are observed for the as-deposited $10 \% \mathrm{Pd}^{-\mathrm{SnO}_{\mathrm{x}}}$ films, whose spectrum shows signals due to $\mathrm{Sn} \mathrm{M}_{4} \mathrm{~N}_{45} \mathrm{~N}_{45}$ transitions at 431.5 and $438.8 \mathrm{eV}$. This is also the case for the oxygen $\mathrm{KL}_{23} \mathrm{~L}_{23}$ transitions which are observed at $518.7 \mathrm{eV}$. The positions of the most prominent tin peaks for the asdeposited 30\% $\mathrm{Pd}-\mathrm{SnO}_{\mathrm{x}}$ films at 425.7 and $433.9 \mathrm{eV}$ (rather than 430 and 437 $\mathrm{eV}$ for metallic tin) indicate that tin is primarily in an oxide form, and the good resolution of the doublet indicates that little or no metallic tin is present [30].

With respect to as-deposited $50 \% \mathrm{Pd}-\mathrm{SnO}_{\mathrm{x}}$ thin films, the positions of tin signals corresponding to $\mathrm{M}_{4} \mathrm{~N}_{45} \mathrm{~N}_{45}$ transitions are again shifted, appearing at 432.7 and $441.8 \mathrm{eV}$, whereas the oxygen KLL transitions are observed at $520.8 \mathrm{eV}$. Some authors $[27,31]$ have attributed this finding to the presence of metallic Sn at the surface which leads to chemically shifted Auger lines. However, in our study no evidence for metallic Sn could be found. The change of the Sn Auger lines may be related to an intermediate and not fully relaxed oxidation state of the $\mathrm{Sn}$ atoms. The results confirm earlier conclusions that the chemical shift of $\mathrm{Sn} \mathrm{M}_{4} \mathrm{~N}_{45} \mathrm{~N}_{45}$ transitions band between $\mathrm{SnO}$ and $\mathrm{SnO}_{2}$ is small and difficult to distinguish [27]. The $\mathrm{C}$ signals at $275 \mathrm{eV}$ are most likely due to residual hydrocarbon contamination from organic precursors during photolysis.

Normally, the values for $\mathrm{Pd}_{45} \mathrm{VV}$ transitions are found between 330$336 \mathrm{eV}$ [32]. In the Pd loaded films prepared here, this MVV Auger structure is found at $327.5 \mathrm{eV}$, and is rather well defined for pure Pd and but not for PdO. It is difficult to locate with precision the maximum of the MVV AES peak for PdO [32]. However, it is clear that its mean kinetic energy position is shifted in this case. The evolution of the $[\mathrm{O}] /[\mathrm{Sn}]$ composition ratio has been evaluated from intensity ratio $\mathrm{I}(\mathrm{O}) / \mathrm{I}(\mathrm{Sn})$ where $\mathrm{I}(\mathrm{Sn})$ represents the peak area of $\mathrm{Sn} \mathrm{M}_{4} \mathrm{~N}_{45} \mathrm{~N}_{45}$ transition and $\mathrm{I}(\mathrm{O})$ the peak area of O KLL transition. This means that the information about the chemical composition of the structure only concerns the relative variation of the $[\mathrm{O}] /[\mathrm{Sn}]$ composition ratio and not its absolute value. This data for each element and a semi quantitative estimate of the composition of the films are shown in Table 1. 

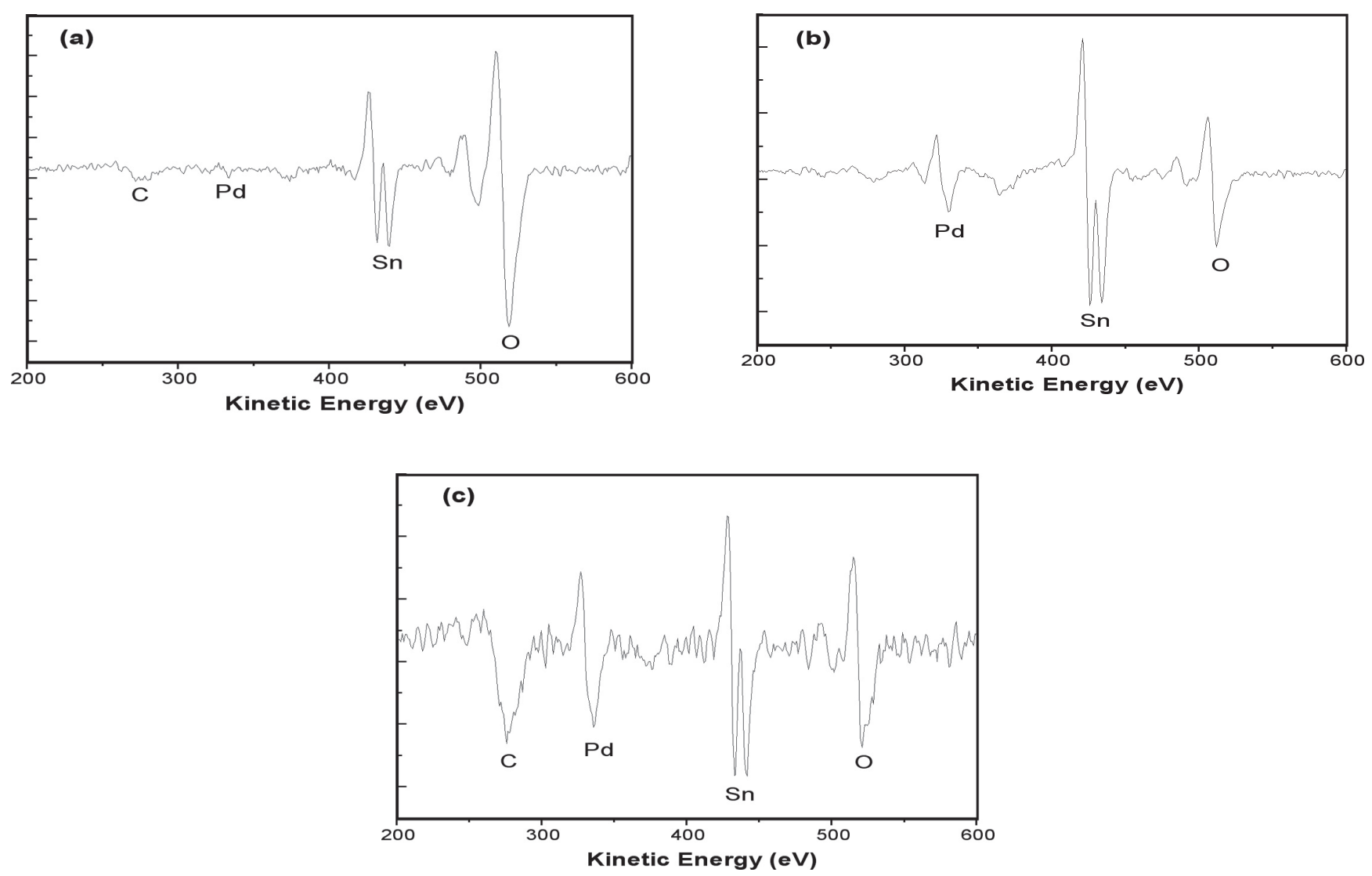

Fig 5. Auger survey spectra of photodeposited $\mathrm{SnO}_{\mathrm{x}}$ films loaded with a) $10 \% \mathrm{Pd}$, b) $30 \% \mathrm{Pd}$ and c) $50 \% \mathrm{Pd}$.

Table1. AES and AFM data for as-deposited Pd and Pt loaded $\mathrm{SnO}_{\mathrm{X}}$ films.

\begin{tabular}{|c|c|c|c|c|c|c|c|}
\hline & $\mathrm{SnO}_{\mathrm{x}}$ & $10 \% \mathrm{Pd} \mathrm{SnO}_{\mathrm{X}}$ & $30 \% \mathrm{Pd} \mathrm{SnO} \mathrm{x}_{\mathrm{x}}$ & $50 \% \mathrm{Pd} \mathrm{SnO} \mathrm{X}_{\mathrm{X}}$ & $10 \% \mathrm{Pt} \mathrm{SnO} \mathrm{X}_{\mathrm{X}}$ & $30 \% \mathrm{Pt} \mathrm{SnO} \mathrm{x}_{\mathrm{x}}$ & $50 \% P t \mathrm{SnO}_{\mathrm{X}}$ \\
\hline & & \multicolumn{3}{|c|}{ Auger Electron Energy (eV) } & & & \\
\hline $\mathrm{Sn} \mathrm{M}_{4} \mathrm{~N}_{45} \mathrm{~N}_{45}$ & 432.2 & 438.8 & 433.9 & 441.8 & 433.3 & 437.7 & 437.3 \\
\hline $\mathrm{Sn} \mathrm{M}_{5} \mathrm{~N}_{45} \mathrm{~N}_{45}$ & 423.8 & 431.5 & 425.7 & 432.7 & 424.8 & 429.8 & 429.4 \\
\hline $\mathrm{O} \quad \mathrm{KL}_{23} \mathrm{~L}_{23}$ & 510.6 & 518.7 & 511.8 & 520.8 & 510.6 & 516.0 & 516.2 \\
\hline $\mathrm{Pd} \mathrm{M}_{45} \mathrm{VV}$ & --- & 333.6 & 330.3 & 336.4 & --- & --- & --- \\
\hline $\mathrm{Pt}$ & & \multicolumn{3}{|c|}{$\%$ Additive AES } & & & \\
\hline $\mathrm{Pd}$ & $\begin{array}{ll}-- \\
\end{array}$ & 7.84 & 22.26 & 37.26 & --- & --- & --- \\
\hline \multirow[t]{2}{*}{$\mathrm{Pt}$} & $\begin{array}{ll}-- \\
\end{array}$ & $\begin{array}{c}-- \\
\end{array}$ & $\begin{array}{l}-- \\
\end{array}$ & 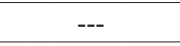 & 12.91 & 28.55 & 53.0 \\
\hline & & & {$[\mathbf{O}] /[\mathbf{S n}]$} & & & & \\
\hline Rms (nm) & 17.7 & 34.9 & 54.4 & 28.0 & 19.7 & 3.60 & 14.8 \\
\hline
\end{tabular}

${ }^{1}$ sputtering with $\mathrm{Ar}^{+}$for $120 \mathrm{~s}$ 
In the table, from the evolution of the $[\mathrm{O}] /[\mathrm{Sn}]$ composition ratio one can observe that varies between 1.20 and 0.78 for most part of the photodeposits obtained. This means that the films consist of mixed phases of tin oxide, favoring mainly the formation of $\mathrm{SnO}$.

Figs 6(a), 6(b) and 6(c) compare typical morphologies of the as-deposited revealed by AFM, and the images presented correspond to samples of $\mathrm{SnO}_{\mathrm{x}}$ films loaded with 10,30 and $50 \%$ of Pd respectively. We may observe in the $10 \% \mathrm{Pd}-\mathrm{SnO}_{\mathrm{x}}$ films a flat surface with some Pd clusters with sizes ranging between 50 and $2000 \mathrm{~nm}$ aprox. deposited in some sectors over the surface.

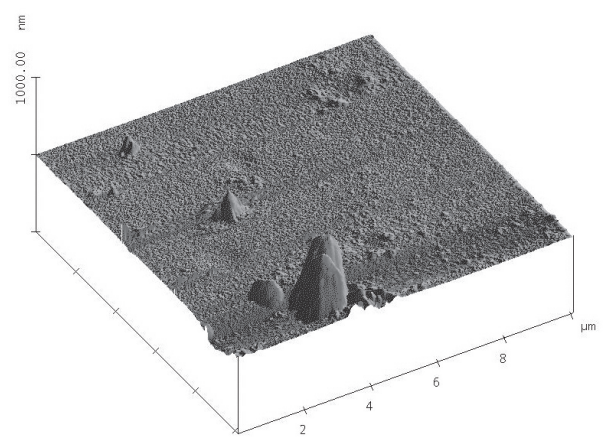

(a)

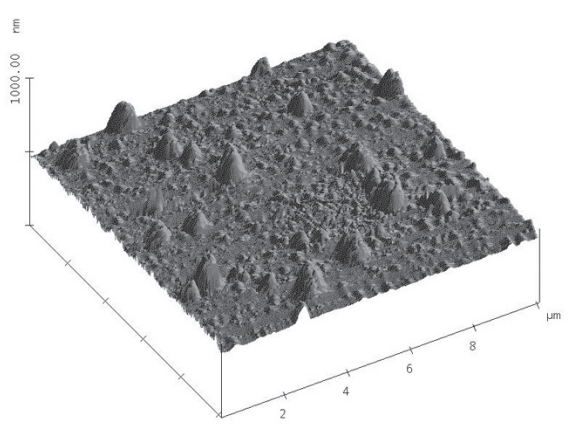

(b)

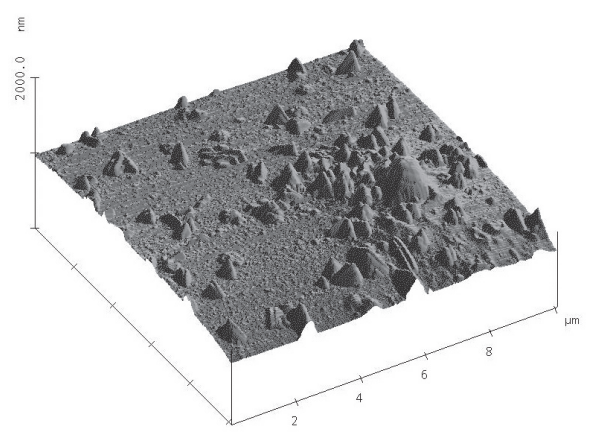

(c)

Fig 6. AFM micrographs of as-deposited Pd loaded $\mathrm{SnO}_{\mathrm{x}}$ films on $\mathrm{Si}(100)$ (a) $10 \%$ Pd loaded (b) $30 \%$ Pd loaded and (c) $50 \%$ Pd loaded tin oxide. Image size $10 \times 10 \mu \mathrm{m}$. With $\mathrm{z}$-scale of $1000.0 \mathrm{~nm}$.

The $30 \% \mathrm{Pd}-\mathrm{SnO}_{\mathrm{x}}$ films show a rougher surface with increase agglomeration of clusters, with sizes varying between $50-1000 \mathrm{~nm}$ aprox. These clusters, although smaller than those found for $10 \% \mathrm{Pd}-\mathrm{SnO}_{\mathrm{x}}$, are distributed over a bigger surface area and therefore the rms roughness increases considerably,

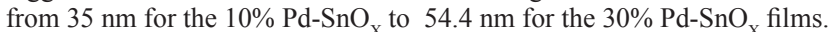

Finally, we can observe that the $50 \% \mathrm{Pd}-\mathrm{SnO}_{\mathrm{x}}$ films present a homogeneus distribution of clusters covering the entire surface. However the size of these clusters diminishes to $20-500 \mathrm{~nm}$ aprox. This translate into smaller rms roughness $(28.0 \mathrm{~nm})$ when compared to $\mathrm{SnO}_{\mathrm{x}}$ films with lower Pd content.

Pt-loaded $\mathrm{SnO}_{\mathrm{x}}$ thin films.

Figs 7(a), 7(b) and 7(c) show the AES survey derivative spectra of $\mathrm{SnO}_{x}$ films loaded with 10,30 and 50\% of Pt respectively. It has been reported that the signals for Sn MNN transitions for Sn/Pt alloys, can be found between 428430 and between 436-437 eV [30,33]. However, these energy displacements can vary depending on the synthesis conditions and composition of the sample. On the other hand, the Pt transitions can be found in a wide range of kinetic energy $(25-300 \mathrm{eV})[30]$.

For the different photodeposits analyzed it was found that the $\mathrm{M}_{4} \mathrm{~N}_{45} \mathrm{~N}_{45}$ and $\mathrm{M}_{5} \mathrm{~N}_{45} \mathrm{~N}_{45}$ transitions assigned to $\mathrm{Sn}$ appear at 433 and $424 \mathrm{eV}$ for the asdeposited $10 \% \mathrm{Pt}-\mathrm{SnO}_{\mathrm{X}}$, and at 437 and $429 \mathrm{eV}$ for the as-deposited $30 \%$ $\mathrm{Pt}^{-\mathrm{SnO}_{\mathrm{x}}}$ and $50 \% \mathrm{Pt}_{-} \mathrm{SnO}_{\mathrm{x}}$. The signals pertaining to oxygen $\mathrm{KL}_{23} \mathrm{~L}_{23}$ transition were located at $510 \mathrm{eV}$ for the $10 \% \mathrm{Pt}_{-} \mathrm{SnO}_{\mathrm{x}}$ films and at $516 \mathrm{eV}$ for the $30 \%$ $\mathrm{Pt}-\mathrm{SnO}_{\mathrm{x}}$ and $50 \% \mathrm{Pt}-\mathrm{SnO}_{\mathrm{x}}$ films. Finally, the peaks associated to Pt in metallic state were found at 62 and $64 \mathrm{eV}$. All these results are shown in Table 1.
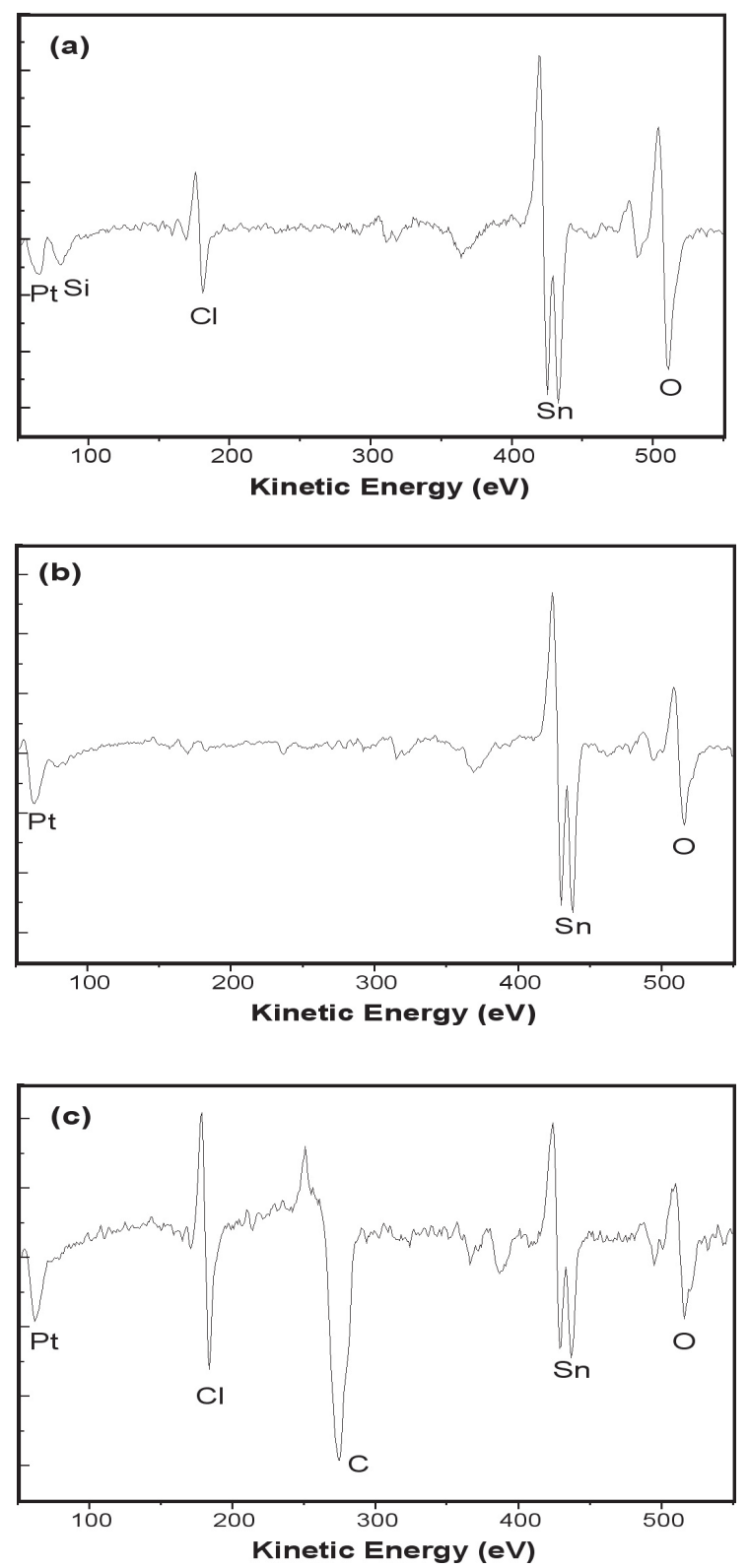

Fig 7. Auger survey spectra of photodeposited $\mathrm{SnO}_{\mathrm{x}}$ films loaded with a) $10 \% \mathrm{Pt}$, b) $30 \% \mathrm{Pt}$ and c) $50 \% \mathrm{Pt}$ 
The $[\mathrm{O}] /[\mathrm{Sn}]$ composition ratio obtained from each signal intensity, fluctuates between 1.58 and 0.71 for the different films. Just as in the previous case, intermediate $\mathrm{Sn}$ oxidation states exist, favoring the formation of $\mathrm{SnO}$, more than the complete formation of $\mathrm{SnO}_{2}$. The AES semi quantitative analysis gave the following results for Pt composition present in the as-deposited films: $12.9,28.6$ and $53.0 \%$, values which correspond to the initial percentages of the mixtures prepared of the precursors $(10,30$ and $50 \%$ of $\mathrm{Pt})$.

Figs. 8(a), 8(b) and 8(c) compares AFM typical morphologies corresponding to as-deposited $\mathrm{SnO}_{\mathrm{x}}$ films loaded with 10,30 and $50 \%$ of Pt respectively. For the $10 \% \mathrm{Pt}-\mathrm{SnO}_{\mathrm{x}}$ films it is observed that the Pt particles are distributed evenly throughout the surface, in comparison to Pd containing films. On the other hand, the size of the Pt particles is small and quite uniform (20-80 nm) compared to Pd clusters having a wide size range $(50-2000 \mathrm{~nm})$. However, the $30 \%$ Pt$\mathrm{SnO}_{\mathrm{x}}$ films present a significant change in surface morphology, with a flat and porous surface in which the Pt clusters are no longer observed indicating that the distribution of Pt on the $\mathrm{SnO}_{\mathrm{x}}$ films appears to be very homogeneous and amorphous. The values of rms roughness for $30 \% \mathrm{Pt}-\mathrm{SnO}_{\mathrm{x}}$ films $(3.60 \mathrm{~nm})$ are lower than those found for $10 \%$ Pt loaded films $(19.7 \mathrm{~nm})$. On the other hand, the $50 \% \mathrm{Pt}-\mathrm{SnO}_{\mathrm{x}}$ films present a less flat and more porous surface, with a rms roughness value of $14.8 \mathrm{~nm}$, and a homogeneous distribution of Pt throughout the surface. These findings are consequent with the AES semi quantitative analysis results, which showed that the percentages of Pt in the initial mixture are maintained in the final deposits. This characteristic can be attributed to the amorphous character shown by the precursor Pt complex when spin coated on the Si substrate. This is not the case for the Pd precursor complex which showed a more crystalline character, and this would explain the formation of clusters in the surface and its random distribution, in the as-deposited Pdloaded $\mathrm{SnO}_{x}$ films.

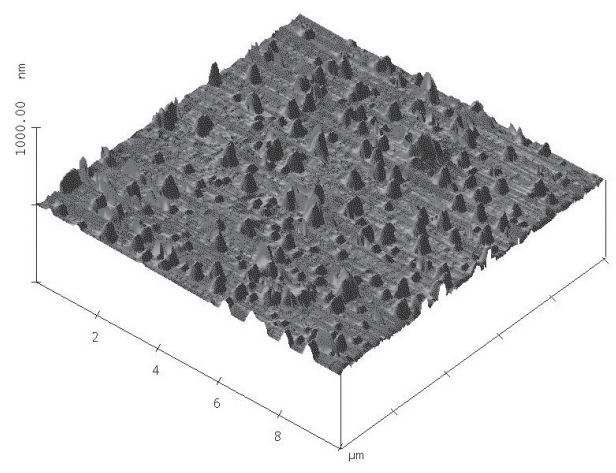

(a)

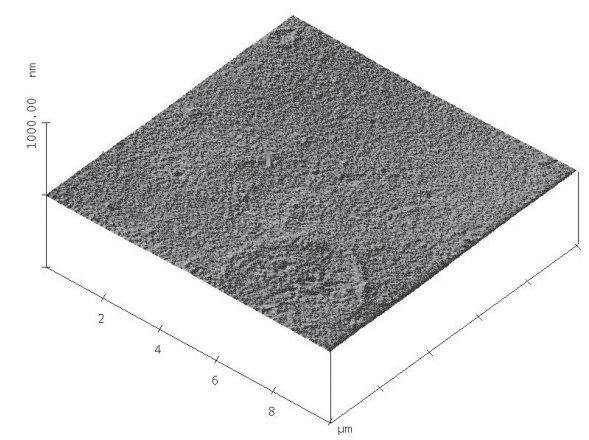

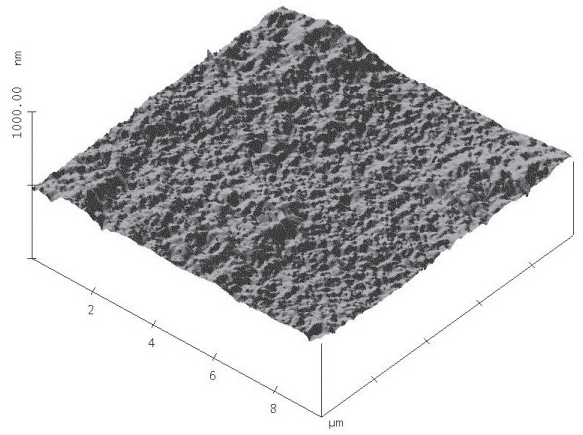

(c)

Fig 8. AFM micrographs of as-deposited $\mathrm{Pt}$ loaded $\mathrm{SnO}_{\mathrm{x}}$ films on $\mathrm{Si}(100)$ (a) $10 \% \mathrm{Pt}$ loaded (b) $30 \% \mathrm{Pt}$ loaded and (c) $50 \% \mathrm{Pt}$ loaded tin oxide. Image size $10 \times 10 \mu \mathrm{m}$. With z-scale of $1000.0 \mathrm{~nm}$.

The presence of some pollutants such as carbon, may come from the photofragmentation of the precursor complexes during photolysis. The formation of species $\mathrm{MC}^{+}$(where $\mathrm{M}=\mathrm{Pd}$ or $\mathrm{Pt}$ ) has been documented [34]. The absorption of light may cause dissociation of the $\mathrm{M}-\mathrm{O}$ bonds and the formation of $\mathrm{MC}^{+}$, probably from the abstraction of a carbon atom from another $\beta$-diketonate complex.

\section{CONCLUSIONS}

Pd and Pt loaded $\mathrm{SnO}_{\mathrm{x}}$ thin films have been successfully prepared by direct UV irradiation of amorphous films of $\beta$-diketonate complexes on $\mathrm{Si}(100)$ substrates. As-deposited films were characterized by Auger Electronic Spectroscopy (AES). Sn $\mathrm{M}_{4} \mathrm{~N}_{45} \mathrm{~N}_{45}$ Auger transitions of as-deposited and thermally treated films show significant differences in peak shape, which are most likely due to differences in oxidation states of Sn. The Auger peak intensity ratios of $\mathrm{O} \mathrm{KL} \mathrm{L}_{23} \mathrm{~L}_{23}$ to $\mathrm{Sn} \mathrm{M}_{4} \mathrm{~N}_{45} \mathrm{~N}_{45}$ showed that as-deposited films consist of mixed tin oxide phases whereas annealed films consist mainly of single phase $\mathrm{SnO}_{2}$. This is important since it has been reported that tin oxide films with mixed phases are better than single phase films for gas sensors [35].

The surface characterization using Atomic Force Microscopy (AFM) revealed that the microstructure of the films was significantly affected by loading with noble metal. Metal-loaded tin oxide films have a much rougher surface than unloaded tin oxide films, with rms roughness values ranging from 28-54 nm for $\mathrm{Pd}-\mathrm{SnO}_{\mathrm{x}}$ films to $3.6-20 \mathrm{~nm}$ for $\mathrm{Pt}-\mathrm{SnO}_{\mathrm{x}}$ films. As-deposited $\mathrm{Pt}-\mathrm{SnO}_{\mathrm{X}}$ films present homogeneously distributed grains and nanosize porosity whereas as-deposited $\mathrm{Pt}-\mathrm{SnO}_{\mathrm{x}}$ films showed a random distribution of grain size. These results demonstrate the potential use of these photochemically produced semiconductor oxide films in gas-sensing devices.

\section{ACKNOWLEDGMENTS}

This research was supported by FONDECYT, Chile (Project No. 1010390) and Pontificia Universidad Católica de Valparaíso (Project D.I. No. 125.735). G. Cabello thanks MECESUP Chile (Project UCO 9905) for a doctoral fellowship. 


\section{REFERENCES}

[1] A.S. Ryzhikov, R.B. Vasiliev, M.N. Rumyantseva, L.I. Ryabova, G.A. Dosovitsky, A.M. Gilmutdinov, V.F. Kozlovsky, A.M. Gaskov, Mater. Sci. Eng. B 96 (2002) 268.

[2] H. Gong, Y. Wang, Z. Yan, Y. Yang, Mater. Sci. in Semicond. Proc. 5 (2002) 31 .

[3] H.W. Ryu, B.S. Park, S. Akbar, W.S. Lee, K.J. Hong, Y.J. Seo, D.C. Shin, J.S. Park, G.P. Choi, Sens. Actuators B 96 (2003) 717.

[4] P. Mitra, H.S. Maiti, Sens. Actuators B 97 (2004) 49.

[5] D.H. Kim, S.H. Lee, K.H. Kim, Sens. Actuators B 77 (2001) 427.

[6] C.H Shim, D.S Lee, S.I Hwang, M.B Lee, J.S Huch, D.D Lee, Sens. Actuators B 81 (2002) 176.

[7] M.H. Madhusudhana Reddy, A.N. Chandorkar, Thin Solid Films 349 (1999) 260.

[8] A. Cabot, J. Arbiol, J.R. Morante, U. Weimar, N. Barsan, W. Gopel, Sens. Actuators B $70(2000) 87$.

[9] R. Díaz, J. Arbiol, A. Cirera, F. Sanz, F. Peiro, A. Cornet, J.R. Morante. Chem. Mater, 13 (2001) 4362.

[10] R. Diaz, J. Arbiol, F. Sanz, A. Cornet, J.R. Morante, Chem. Mater. 13 (2002) 3277.

[11] C. Bittencourt, E. Llobet, P. Ivanov, X. Correig, X. Vilanova, J. Brezmes, J. Hubalek, K. Malysz, J.J. Pireaux, J. Calderer, Sens. Actuators B 97 (2004) 67.

[12] S. Gupta, R. K. Roy, M.P.M. Pal Chowdhury, A. K. Pal, Sens. Actuators B 75 (2004) 111.

[13] S. Capone, P. Siciliano, F. Quaranta, R. Rella, M. Epifani, L. Vasanelli, Sens. Actuators B 77 (2001) 503.

[14] B. Esfandyarpour. S. Mohajerzadeh, S. Famini, A. Khodadadi, E. Asl Soleimani, Sens. Actuators B 100 (2004) 190.

[15] P. Montmeat, C. Pijolat, G. Tournier, J-P. Viricelle, Sens. Actuators B 84 (2002) 148.

[16] A. Salehi, Sens. Actuators B 96 (2003) 88.

[17] G.E. Buono-Core, M. Tejos, J. Lara, F. Aros, R.H. Hill, Mater. Res. Bull. 34 (1999) 2333; G.E. Buono-Core, G. Cabello, B. Torrejon, M. Tejos, R.H. Hill, Mater. Res. Bull. 40 (2005) 1765; G.E. Buono-Core, M. Tejos, G. Cabello, N. Guzman, R.H. Hill, Mater. Chem. Phys. 96 (2006) 98.
[18] G.E. Buono-Core, M. Tejos, G. Alveal, J. Mater. Sci. 35 (2000) 4873; G.E. Buono-Core, M. Tejos, G. Cabello, F. Aros, R.H. Hill, Bol. Soc. Chil. Quim. 47 (2002) 495.

[19] G.E. Buono-Core, G. Cabello, J.L. Cayon, M. Tejos, R.H. Hill, J. Chil. Chem. Soc. 50 (2005) 541

[20] J T. Adams, C.R. Hauser, J. Am. Chem. Soc. 66 (1944) 1220.

[21] C.R. Hauser, T.M. Harris, J. Org. Chem. 30 (1965) 1007.

[22] Kai Ming Chi, Chia- Ch'I Lin, Ya-Hui Lu. Ju Hsiou Liao, J. Chin. Chem. Soc. 47 (2002) 425.

[23] H.K. Shin, K.M. Chi, J. Farkas, M.J. Hampden, T.T. Kodas, E.N. Duesler, Inorg. Chem. 31 (1992) 424.

[24] L.Weibin, C.B. Wiegand, R.G. Nuzzo, G.S. Girolamy, J. Am. Chem. Soc. 118 (1996) 5977.

[25] B. Marciniak, G. Buono-Core, J. Photochem. Photobiol. A: Chemistry 52 (1990) 1.

[26] R. L. Lintvedt in "Concepts of Inorganic Photochemistry," A.W. Adamson y P.D. Fleischauer Eds.. John Wiley \& Sons, New York, Chap. 7, p. 299 (1975).

[27] A. Lin, N. Armstrong, T. Kuwana, Anal. Chem. 49 (1977) 1228.

[28] S.K. Sen, S. Sen, C.L. Bauer, Thin Solid Films 82 (1981) 157.

[29] W.K. Choi, J.S. Cho, S.K. Song, H.J. Jung, S.K. Koh, K.H. Yoon, C.M. Lee, M.C. Sung, K. Jeong, Thin Solid Films 304 (1997) 85.

[30] G. Hoflund, D. Asbury, Thin Solid Films 129 (1985) 139.

[31] R. Ramamoorthy, M.K. Kennedy, H. Nienhaus, A. Lorke, F.E. Kruis, H. Fissan, Sens. Actuators B 88 (2003) 281.

[32] M. Brun, A. Berthet, J.C. Bertolini, J. Electron Spectrosc. Related Phenom. 104 (1999) 55.

[33] R. Bouwman, L.H. Toneman, A.A. Holscher, Surf. Sci. 35 (1973) 8.

[34] P. Muraoka, D. Byun, J.I. Zink, Coord. Chem. Rev. 208 (2000) 193.

[35] S.H. Park, Y.C. Son, W.S. Willis, S.L. Suib, K.E. Creasy, Chem. Mater. 10 (1998) 2389. 